\title{
Construction of a Full-Length Enriched cDNA Library and Preliminary Analysis of Expressed Sequence Tags from Bengal Tiger Panthera tigris tigris
}

\author{
Changqing Liu ${ }^{1,2, \dagger}$, Dan Liu ${ }^{3, \dagger}$, Yu Guo ${ }^{2}$, Taofeng Lu ${ }^{1}$, Xiangchen $\mathrm{Li}^{1}$, Minghai Zhang ${ }^{4}$, \\ Jianzhang $\mathrm{Ma}^{4}$, Yuehui Ma ${ }^{1}$ and Weijun Guan ${ }^{1, *}$
}

1 Institute of Animal Science, Chinese Academy of Agricultural Sciences, Beijing 100193, China; E-Mails: lcq7813@hotmail.com (C.L.); taofenglu@yahoo.com.cn (T.L.); nobelli@126.com (X.L.); Yuehui.ma@263.net (Y.M.)

2 Department of Bioscience, Bengbu Medical College, Bengbu 233000, China; E-Mail: ily0720@126.com

3 The Northeast Tiger Wooden Land of Heilongjiang, Harbin 150028, China; E-Mail: liudan_1964@sina.com

4 College of Wildlife Resource, Northeast Forestry University, Harbin 150028, China; E-Mails: zhangminghai2004@126.com (M.Z.); jianzhangma@163.com (J.M.)

$\dagger$ These authors contributed equally to this work.

* Author to whom correspondence should be addressed; E-Mail: wjguan86@hotmail.com; Tel.: +86-10-6281-5992; Fax: +86-10-6289-5371.

Received: 21 November 2012; in revised form: 24 April 2013 / Accepted: 25 April 2013 / Published: 24 May 2013

Abstract: In this study, a full-length enriched cDNA library was successfully constructed from Bengal tiger, Panthera tigris tigris, the most well-known wild Animal. Total RNA was extracted from cultured Bengal tiger fibroblasts in vitro. The titers of primary and amplified libraries were $1.28 \times 10^{6} \mathrm{pfu} / \mathrm{mL}$ and $1.56 \times 10^{9} \mathrm{pfu} / \mathrm{mL}$ respectively. The percentage of recombinants from unamplified library was $90.2 \%$ and average length of exogenous inserts was $0.98 \mathrm{~kb}$. A total of 212 individual ESTs with sizes ranging from 356 to $1108 \mathrm{bps}$ were then analyzed. The BLASTX score revealed that $48.1 \%$ of the sequences were classified as a strong match, $45.3 \%$ as nominal and $6.6 \%$ as a weak match. Among the ESTs with known putative function, $26.4 \%$ ESTs were found to be related to all kinds of metabolisms, $19.3 \%$ ESTs to information storage and processing, 11.3\% ESTs to posttranslational modification, protein turnover, chaperones, $11.3 \%$ ESTs to transport, 9.9\% ESTs to signal transducer/cell 
communication, 9.0\% ESTs to structure protein, 3.8\% ESTs to cell cycle, and only $6.6 \%$ ESTs classified as novel genes. By EST sequencing, a full-length gene coding ferritin was identified and characterized. The recombinant plasmid pET32a-TAT-Ferritin was constructed, coded for the TAT-Ferritin fusion protein with two $6 \times$ His-tags in $N$ and $C$-terminal. After BCA assay, the concentration of soluble Trx-TAT-Ferritin recombinant protein was $2.32 \pm 0.12 \mathrm{mg} / \mathrm{mL}$. These results demonstrated that the reliability and representativeness of the cDNA library attained to the requirements of a standard cDNA library. This library provided a useful platform for the functional genome and transcriptome research of Bengal tigers.

Keywords: Bengal tiger; Panthera tigris tigris; fibroblast cell line; SMART cDNA library; expressed sequence tags

\section{Introduction}

Tiger (Panthera tigris Linnaeus, 1758) is a special species only found in Asia and considered as a symbol of beauty, power, and bravery [1]. There are four generally accepted tiger subspecies in China, Siberian tigers ( $P$. t. altaica), Indochinese tigers ( $P$. t. corbetti), South China tigers ( $P$. t. amoyensis), and Indian or Bengal tigers (P. t. tigris). Today an estimated fewer than 4580 Bengal tigers survive in Bangladesh, Nepal, eastern India, Bhutan, Burma and southwest China, and less than 30 now exist in China $[2,3]$.

The tiger is warranted the highest level of protection by the Convention on International Trade in Endangered Species of Wild Fauna \& Flora (CITES). In 1989, the Chinese government placed the Bengal tiger into category I of National Protected Animal breed. In order to preserve the wealth of biodiversity in China, and to uncover the complex underlying interactions between organisms and environment, there is a very urgent need to commence rigorous conservation of endangered species. The study of full-length cDNAs remains an indispensable approach for structural and functional genome annotations. However, up to now, only about 25 functional genes and EST sequences of Panthera tigris have been cloned and partially studied according to the latest data of NCBI, and information with reference to cDNA library of $P$. t. tigris is scarce. To identify more genes of Bengal tiger, including the characterization of specific expressed, new or unknown functional genes and further study of their functions, construction of full-length cDNA libraries of Bengal tiger is an efficient method [4,5].

In this paper, we have cryopreserved Bengal tiger this international protected genomic resource at cellular level by establishing Bengal tiger fibroblasts cell line for the purpose of providing a convenient and effective resource for genome and transcriptome research. Meanwhile, a study on a normalized full-length cDNA library construction and preliminary analysis of ESTs from Bengal tiger fibroblast cells conducted in our laboratory is hereby described. 


\section{Results}

\subsection{Cell cultures and Characteristic Tests}

We used a primary explanting technique and cell cryogenic preservation technology to establish the Bengal tiger fibroblast cell line and proceeded to biological and genetic detection. The culture conditions were optimal, and the cells were healthy (Figure 1A-D). The test results of the bacteria, virus and Mycoplasma were negative (Figure 1E). To conserve genomic character of Bengal tiger, the fibroblast must maintain diploid character similar with the cells in vivo. Chromosome analysis showed that the frequency of cell chromosome number of $2 n=38$ was $90.6 \%-92.2 \%$ in passages 1 to 3 , which indicated that culture in vitro effects the heritage of cells slightly, supporting the theory that the cell line was a steady diploid one(Figure 1F).

Figure 1. Morphology, Mycoplasma contamination and karyotype of Bengal tiger cell line. (A) Primary cells $(\times 100)$, the cells were typical long spindle-shape; (B) Subcultured cells $(\times 100)$; (C) Cells before cryopreservation $(\times 100)$; (D) Cells after recovery $(\times 100)$; (E) Mycoplasma contamination stained with Hoechst33258 and positive control of Mycoplasma contamination; (F) G-band chromosome at metaphase (Left) and karyotype (Right) $(\lesssim, \times 1,000)$.
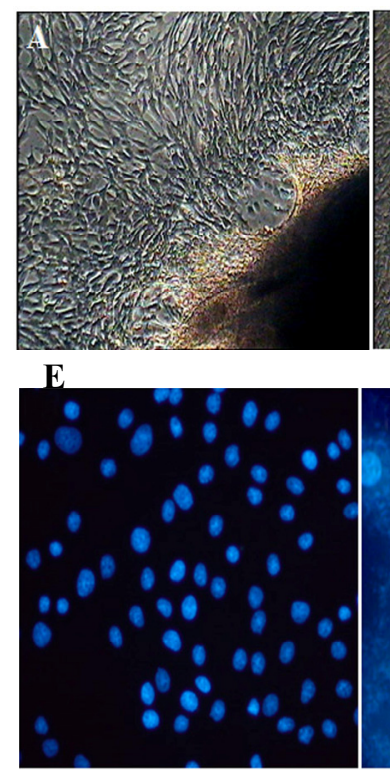
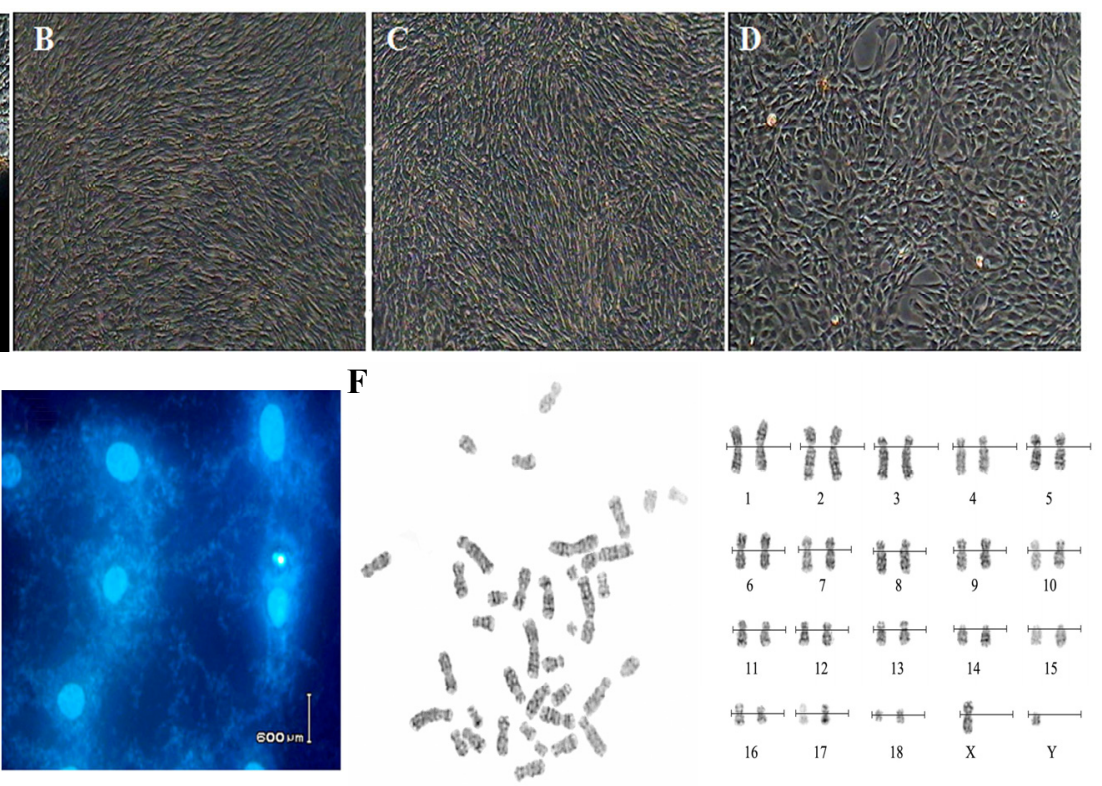

\subsection{Total RNA Extraction and LD-PCR}

The ratio of $\mathrm{OD}_{260} / \mathrm{OD}_{280}$ for total RNAs was approximately $1.96-2.08$ and the concentrations were $0.926-1.231 \mu \mathrm{g} / \mu \mathrm{L}$. As shown in Figure $2 \mathrm{~A}$, two bright bands of $18 S$ rRNA and $28 S$ rRNA can be seen clearly, indicating that the total RNA was pure, integrated and stable enough for cDNA library construction. The stability of RNA was verified by incubating a small sample at $37^{\circ} \mathrm{C}$ for two and three hours. There were little differences among the incubated and the fresh samples. Two micrograms of total RNA was subjected to reverse transcription for synthesis of the first and double-stranded cDNAs for LD-PCR. As shown in Figure 2B, the ds-DNA appeared as a smear of bands of $0.5-4 \mathrm{~kb}$ on the gel. 
Figure 2. Total RNA from fibroblast cells of Bengal tiger and long distance PCR (LD-PCR). (A) Total RNA from fibroblast cells of Bengal tiger. Lane 1: a sample of $5 \mu \mathrm{L}$ total RNA; Lane 2, 3: two samples incubated at $37^{\circ} \mathrm{C}$ for $2 \mathrm{~h}$ and $3 \mathrm{~h}$, respectively; (B) The products of LD-PCR. M: marker; Lane 1, 2: the products of LD-PCR with 22 cycles.
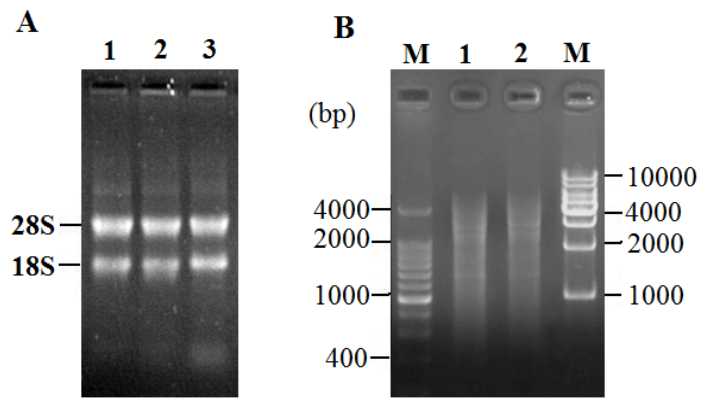

\subsection{Characterization of cDNA Library}

cDNA-fragments smaller than 500 bp and longer than 4000 bp were eliminated by cDNA fractionation using a CHROMA SPIN-400 column to avoid the library having a preponderance of very small inserts and/or non-recombinant clones(Figure 3A). The titers of primary and amplified libraries were $1.28 \times 10^{6} \mathrm{pfu} / \mathrm{mL}$ and $1.56 \times 10^{9} \mathrm{pfu} / \mathrm{mL}$ respectively. The recombination efficiency of the amplified libraries was $90.2 \%$. The insert ratio and the average length of inserted fragments were measured by PCR, as shown in Figure 3B. The average size was approximately $0.98 \mathrm{~kb}, 1-2 \mathrm{~kb}$ in $58.8 \%$ and $0.5-1.0 \mathrm{~kb}$ in $38.3 \%$, suggesting that the insertion fragments harbored most of the mRNAs and reached the requirement for further studies on gene structure, translation, and expression.

Figure 3. cDNA size fractionation and Recombinant clones screening. (A) cDNA size fractionation by CHROMA SPIN-400. M: DNA marker; 1-16: tube serial number; (B) Recombinant clones screening within the library. M: DNA marker; 1-23: PCR products for clones selected randomly.
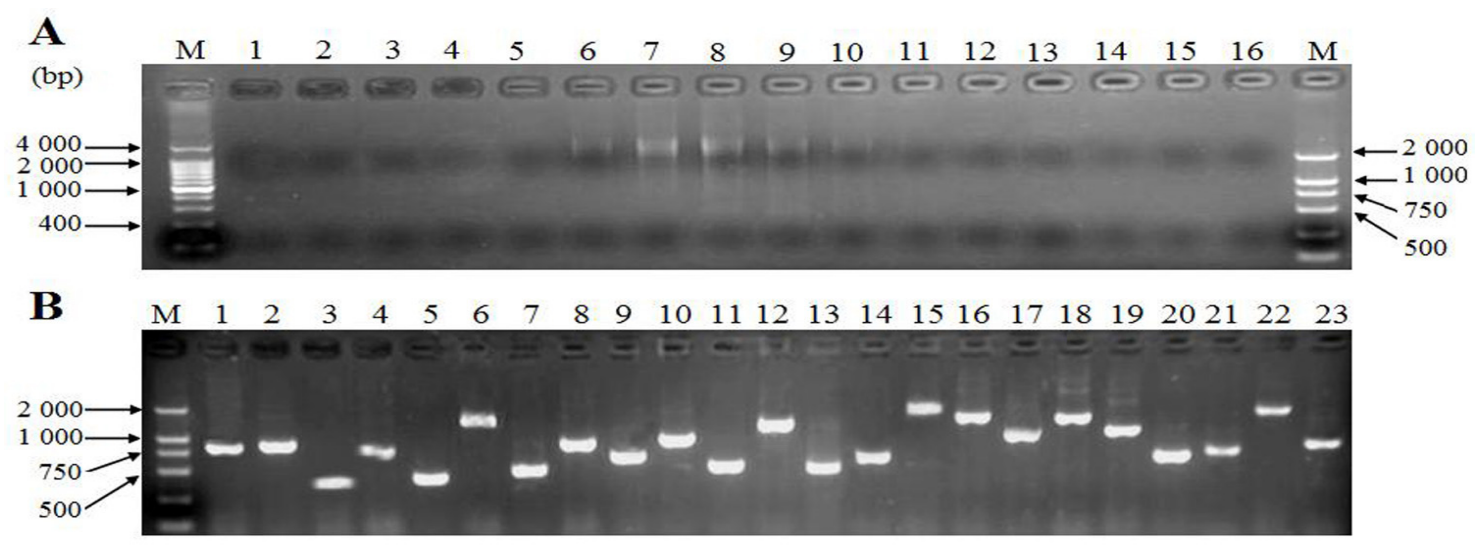

\subsection{Generation of Expressed Sequence Tags and Sequence Analysis}

The primary cDNA library, instead of the amplified library, was used for generation of ESTs to reduce the redundancy of cDNA clones as only a small number of ESTs were targeted through random 
selection. Four hundred and fifty-six white clones were picked randomly for EST sequencing. After removal of the vector sequences and low-quality sequences, 354 effective sequences from the total cDNA sequences were obtained, a total of 212 individual ESTs ranging from 356 to 1108 nucleotides in length were analyzed and partly deposited in the GenBank under accession No. from JZ331652 to JZ331708.

Figure 4. Comparison of classification of ESTs from P. t. tigris cDNA library based on their putative functions with those of $H$. sapiens. Two cDNA data sets were classified into functional groups by using the Clusters of Orthologous Group (COG) database.
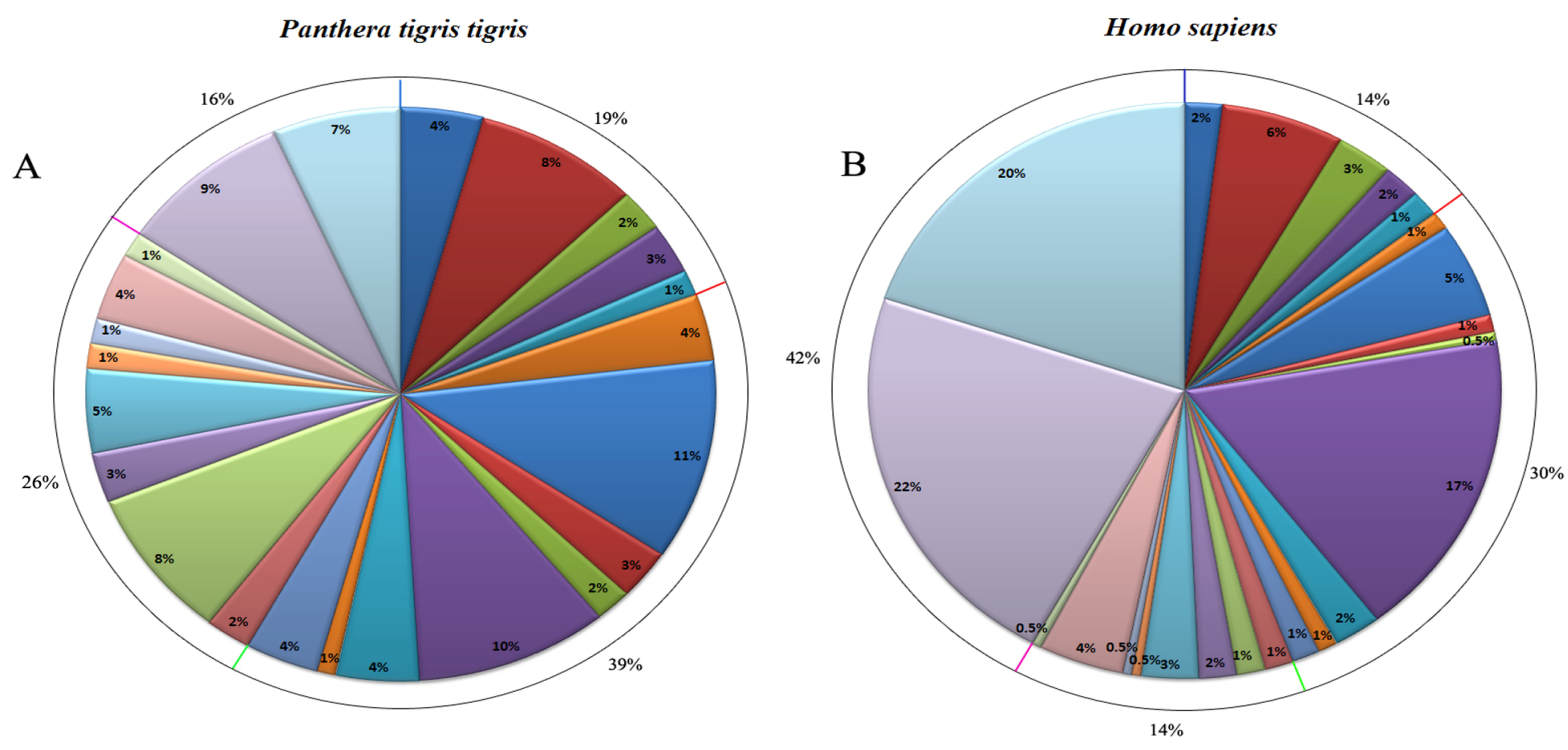

\begin{tabular}{|c|c|c|}
\hline $\begin{array}{l}\square \\
\square \\
\square \\
\square \\
\square\end{array}$ & $\begin{array}{l}\text { Translation, ribosomal structure and biogenesis } \\
\text { Transcription } \\
\text { DNA replication, recombination and repair } \\
\text { RNA processing and modification } \\
\text { Extracellular structures }\end{array}$ & $\begin{array}{l}\text { INFORMATION STORAGE } \\
\text { AND PROCESSING }\end{array}$ \\
\hline $\begin{array}{l}\square \\
\square \\
\square \\
\square \\
\square \\
\square \\
\square \\
\square\end{array}$ & $\begin{array}{l}\text { Cell division and chromosome partitioning } \\
\text { Posttransla tional modification, protein turnover, chaperones } \\
\text { Cell envelope biogenesis, outer membrane } \\
\text { Cell motility and secretion } \\
\text { Signal transduction mechanisms } \\
\text { Intracellular trafficking, secretion, and vesicular transport } \\
\text { nuclear structure } \\
\text { cytoskeleton }\end{array}$ & $\begin{array}{l}\text { CELLULAR PROCESSES } \\
\text { AND SIGNALING }\end{array}$ \\
\hline $\begin{array}{l}\square \\
\square \\
\square \\
\square \\
\square \\
\square \\
\square \\
\square\end{array}$ & $\begin{array}{l}\text { Inorganic ion transport and metabolism } \\
\text { Energy production and conversion } \\
\text { Carbohydrate transport and metabolism } \\
\text { Amino acid transport and metabolism } \\
\text { Nucleotide transport and metabolism } \\
\text { Coenzyme metabolism } \\
\text { Lipid metabolism } \\
\text { Secondary metabolites biosynthesis, transport and catabolism }\end{array}$ & METABOLISM \\
\hline & $\begin{array}{l}\text { General function prediction only } \\
\text { Function unknown }\end{array}$ & POORLY CHARACTERIZED \\
\hline
\end{tabular}

The distribution of ESTs from P. t. tigris cDNA library revealed that 108 (48.1\%) of them were classified as strong matches to sequences in the non-redundant protein database (Nr) for the highest match with a $E$-value less than $10^{-25}$, meanwhile 96 (45.3\%) ESTs were nominal with $E$-value for the highest match between $10^{-10}$ and $10^{-25}$, and $14(6.6 \%)$ ESTs were weak with $E$-value for the highest match greater than $10^{-10}$ or no significant similarity to sequences in the database. Based on identification of Clusters of Orthologous Group of protein (COGs), 212 ESTs were assigned to COGs by BLASTX. 
The proportion pattern of each COG subcategory was similar between P. t. tigris and Homo sapiens. Among the ESTs with known putative function, 56 (26.4\%) ESTs were found to be related to all kind of metabolisms, $41(19.3 \%)$ ESTs to information storage and processing, $24(11.3 \%)$ ESTs to posttranslational modification, protein turnover, chaperones, $24(11.3 \%)$ ESTs to transport, $21(9.9 \%)$ ESTs to signal transducer/cell communication, 19 (9.0\%) ESTs to structure protein, 8 (3.8\%) ESTs to cell cycle, and only 14(6.6\%) ESTs were "unknown protein" with no significant matches or unknown proteins (Figure 4).

\subsection{Cloning and Sequence Analysis of Bengal Tigers Ferritin cDNA}

The full-length ferritin cDNA was 948 bp, including a 5'-untranslated region (UTR) of $219 \mathrm{bp}$, a 3'-noncoding region of $183 \mathrm{bp}$ with a canonical polyadenylation signal sequence AATAAA and a poly (A) tail, and an open reading frame (ORF) of 546 bp encoding a polypeptide of 181 amino acids (Figure 5). The molecular weight of the protein was $21116.6 \mathrm{Mr}$, and the theoretical isoelectric point 5.66. The 5'-UTR contained a putative iron responsive element (IRE) sequence ( -189 to -157 , TCCTGCTTCAACAGTGCTTGAACGGAACCCGGC), which could be folded into a stem-loop structure for the binding site of iron regulatory protein (IRP), indicated that the expression of P.tigris ferritin was regulated at the translational level by iron. One stem loop structure was found in the 5'-UTR, which consisted of a six-nucleotide loop (CAGUGC) in agreement with the structures from other species such as Homo sapiens H [6], Bos Taurus [7], Equus caballus [8] and Sus scrofa [9]. The ferritin of the Panthera tigris has two conserved metal binding sites of the ferritin family members YASYV (T) YL (M,Q) and EK (R) S (N) VNQS.

Figure 5. Nucleotide and deduced amino acid sequences of Panthera tigris ferritin subunit (GenBank accession No.GQ891094). Seven boxed residues represented a tentatively active site of ferroxidase. The polyadenylation signal was in bold and the poly (A) tail was underlined. Iron associated residue (Try30) was in shaded square.

\footnotetext{
1 GAC AGT CTT CGC GGA GAG TCG CCG CGG TTT CCT GCT TCA ACA GTG CTT GAA CGG AAC CCG 61 GCT GCT CGT CCC CCC CTC ACC CCG GCC GGC CAC TCA GAG CCA GCC TTC GTC ACC ACT TGA 121 CAG CGC CCT CCG ACC GGC CCA AGG TCC CCG CCG CCA CTC CAG CGC CGC TCA GCC GTC GCC 181 GCC GCC ACC ACC ACC ACC GCC CCT TTT CAG CCG CCC ACC ATG ACG ACC GCA TCC CCC TCG $\begin{array}{llllllllll}M & T & T & A & S & P & S\end{array}$ 


\subsection{Expression and Purification of Trx-TAT-Ferritin Fusion Protein}

The final plasmid of pET32a-TAT-Ferritin, coded for the TAT-Ferritin fusion protein with two $6 \times$ His-tags in N and C-terminal, was constructed. The expression of Trx-TAT-Ferritin recombinant protein increased with the extension of culture time (Figure 6A). Samples obtained from each purification step were subjected to SDS-PAGE. Approximately $45 \mathrm{kDa}$ of protein band corresponded in size to the full-length form of Trx-TAT-Ferritin fusion protein. The optimal induction requirement for the recombinant protein was $0.1 \mathrm{mM}$ for $6 \mathrm{~h}$. After induction for $6 \mathrm{~h}$, the expression media of Trx-TAT-Ferritin was concentrated to 50 fold by resuspending the pellet in $4 \mathrm{~mL}$ of BugBuster reagent, the tagged proteins were purified through Ni-NTA His•Bind Resin under native conditions, the larger number of soluble proteins appeared in the first wash, and declined gradually in the following steps (Figure 6B). After BCA assay, the concentration of Trx-TAT-Ferritin recombinant protein was $2.32 \pm$ $0.12 \mathrm{mg} / \mathrm{mL}$.

Figure 6. The expression and purification of Trx-TAT-Ferritin recombinant protein. (A) Protein expression of Trx-TAT-Ferritin with different induction time on 1, 2, 4, 6 and $8 \mathrm{~h}$; (B) Trx-TAT-Ferritin purification under native conditions, 1. Flow through, 2-4. first to third column volume.

A

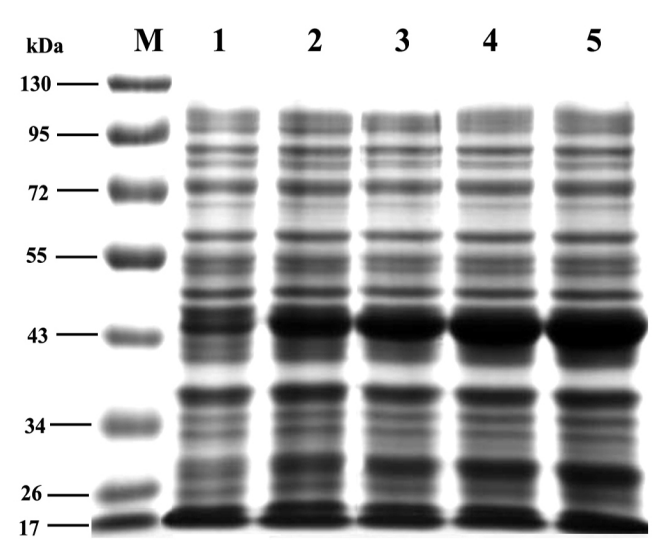

B

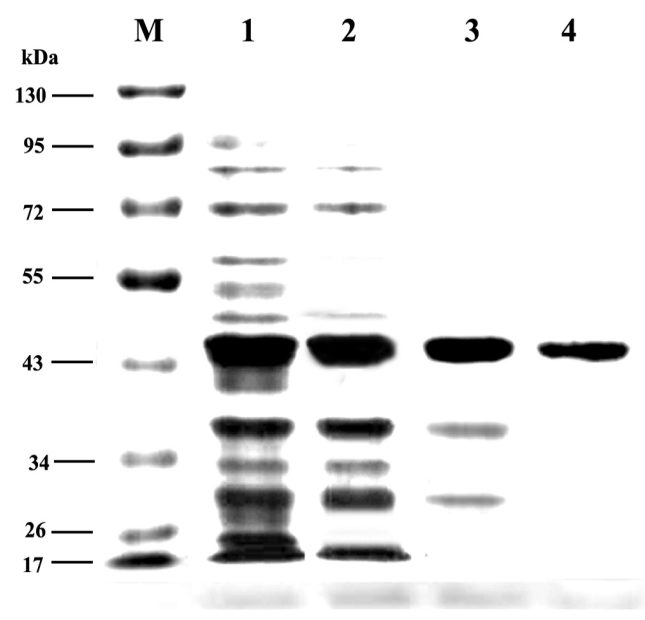

\section{Discussions}

Over the past years, cDNA library construction and analysis is considered to be an indispensable tool for functional genome analysis as it provides much more detailed information on the genomic mechanisms underlying diverse processes of the organism [10]. The major characteristic of cDNA construction by SMART technique could improve the ratio of full-length cDNA sequences. Although the optimal number of cycles for minimizing PCR-induced mutations has not been rigorously tested for SMART library construction, performing three cycles using a suitable polymerase mixture should be sufficient to limit the number of errors to a tolerable level [11,12]. An important characteristic of SMART technique is that it provides a method for producing high-quality and full-length cDNA libraries that preserve the complete 5 ' terminal sequence of mRNA [13]. 


\subsection{Characterization of cDNA Library of Bengal Tiger}

There are three chief aspects that identify the quality of a cDNA library. According to Clareke-Carbon's formula, a cDNA library should contain at least $1.7 \times 10^{5}$ independent clones to ensure that the $99 \%$ low abundance mRNA would be present in the library [14]. The high recombination efficiency is another index of good quality library $[15,16]$. The third aspect is that the average length of inserted cDNA should be no less than $1.0 \mathrm{~kb}$ to ensure the integrity of cDNA. Because selection bias could favor the smaller cDNA, we used fewer PCR cycles to minimize such bias as previously suggested [17]. In our study, up to 22 PCR amplification cycles were used to generate adequate amounts of cDNA for cloning. Most of the cDNA inserts ranged from 500 to $1500 \mathrm{bp}$, and there were a high number of cDNA clones harboring inserts over $3000 \mathrm{bp}$. Such results indicated that the size fraction was an effective selection approach to ensure the full-length cDNA content level in the cDNA library.

The diploid fibroblast cells may be injured and changed in biological characteristics, especially hereditary characteristics, after too many passages and trypsin digestion. Improving culture procedure and decreased the passages $(<4)$ to maintain fibroblast sample character similar with the cells in vivo, we constructed the cDNA library to conserve genomic characteristics of Bengal tiger. The cDNA library constructed in this study will be affluent in the EST library, full-length analysis, the further work of expression identification, location and function in the chromosome will make great promotion for interesting genes associated with its excellent characters of Bengal tiger.

\subsection{Generation and Analysis of ESTS}

cDNA libraries are widely used to identify genes and splice variants, and as a physical resource for full-length clones[18,19]. The SMART library provided a useful resource for the functional genomic research of Bengal tiger and would present some new molecular material for this species as well. Generation of ESTs is an excellent and unique approach in molecular studies as it allows both expression and measurements, and the discovery of new genes to be conducted at the same time. Consequently, analysis of the expression of a large number of genes combined with the knowledge of their functions can facilitate the understanding and allows us to take a glimpse of the overall picture of biological processes in P. t. tigris fibroblast cells. In this study, approximately $93.4 \%$ of the ESTs generated were sequences with known or putative functions, while the remainder was unknown proteins or sequences with no similarities to the databases. These unknown and unclassified ESTs can become candidates for discovering new interesting genes through functional analysis currently being initiated in our laboratory.

\subsection{Expression and Purification of Trx-TAT-Ferritin Fusion Protein}

Recently, TAT technology has become a powerful tool for basic research, and several studies have demonstrated its usefulness for studying the role of proteins, or for targeting specific protein/protein interactions in vitro as well as in vivo. The results in our study demonstrated that Trx-TAT-Ferritin protein was highly expressed after induction for $6 \mathrm{~h}$, with relative molecular weight of $45 \mathrm{kDa}$. In addition, the expressed product was present in a native and soluble form and the yield of the purified 
fusion protein were about $2.32 \pm 0.12 \mathrm{mg} / \mathrm{mL}$. The purified fusion protein provided valuable materials to induce the ferritin protein truncation and expression in cell.

\section{Materials and Methods}

\subsection{Material and Reagents}

Bengal tiger ear tissue samples (12 male and 10 female) were sampled from The Northeast Tiger Wooden Land of Heilongjiang.

\subsection{Cell Cultures and Biological Analysis}

Bengal tiger ear tissue samples (about $1 \mathrm{~cm}^{2}$ in size) were chopped finely into $1 \mathrm{~mm}^{3}$ in size and added DMEM medium with $10 \%$ fetal bovine serum in a $37{ }^{\circ} \mathrm{C}$ incubator with $5 \% \mathrm{CO}_{2}$ to culture fibroblast line. Characteristic tests for established cell line with cell viability, microorganism detection and chromosome analysis: for details of the procedure used see Liu et al. [20].

\section{3. cDNA Library Construction}

Cells were harvested and total RNA was extracted with Trizol reagent (Invitrogen, Carlsbad, CA, USA) when they were in the period of passage 3. First and double-strand cDNAs were synthesized according to the protocol of the SMART cDNA Library Construction kit (Clontech, Palo Alto, CA, USA). Subsequently approximately $2 \mu \mathrm{L}$ of first strand cDNA sample was amplified using long distance PCR (LD-PCR). The first four peak fractions containing cDNA ( $>500 \mathrm{bp}$ ) were pooled together using column chromatograph with CHROMA SPIN-400 medium. The cDNA was ligated to $\lambda$ TriplEx 2 vector (1:1.5) and the ligation was packaged with Gigapack III Gold Packaging extract.

\subsection{Titration of the Primary Library}

The number of clones was counted to calculate the library titer according to the formula: $\mathrm{pfu} / \mathrm{mL}=$ number of plaques $\times$ dilution factor $\times 10^{3} \mu \mathrm{L} / \mathrm{mL}$ ( $\mu \mathrm{L}$ of diluted phage plated). The recombination efficiency was identified by blue/white screening in E.coli XL1-Blue. Colony PCR was used to confirm the size of inserted fragments in the library. After amplification, the completed cDNA libraries were stored in $7 \%$ dimethyl sulfoxide at $-80{ }^{\circ} \mathrm{C}$.

\subsection{Sequence Analysis Method}

cDNA clones were selected randomly from the cDNA library and single-pass sequenced at the 5 ' end on an ABI 3730 Genetic Analyzer (Applied Biosystems, Foster City, CA, USA). A large-scale EST sequencing project for Bengal tiger was initiated to identify and functionally annotate as many unique transcripts as possible. The processed cDNA sequences were used to perform the BLAST search at the GenBank database to compare all available ESTs and genes to date [21]. BLASTX results with bit scores greater than 80 and $E$-values of less than $10^{-10}$ were generally regarded as significant match [22-24]. According to sequencing results of the Bengal tiger cDNA library, 4 ferritin EST 
sequences were obtained and assembled the full-length ferritin cDNA. The ferritin coding regions and domains were predicted online with ORFfinder and SMART [22].

\subsection{Expression and Purification of pET32a-TAT-Ferritin}

TAT protein transduction domain was designed and fused to the N-terminus of Ferritin by PCR method, using specific primers (Ferritin sense: CCA TGG CTT ATG GTC GTA AAA AAC GTC GTC AGC GTC GTC GTA TGA CGA CCG CAT CCC CCT CG and Ferritin antisense: CTCGAG ACT GTC ACT GTG TTT CAG GGT). The amplified fragment was inserted into pET32a expression vector (Novagen, Darmstadt, Germany) Nco I-Xho I sites and transferred into BL21 (DE3) cells. The recombinant protein TAT-Ferritin was expressed in BL21 cells by induction with IPTG at $1-8 \mathrm{~h}$. The expression condition was optimized, soluble proteins were obtained using BugBuster protein extraction reagent (Novagen), purification of proteins were performed by Ni-NTA His•Bind affinity chromatography, the final protein was sterilized by filtration with $0.2 \mu \mathrm{m}$ of filter membrane and quantitated using BCA assay.

\section{Conclusions}

In conclusion, by cryopreserving nationally protected Bengal tiger cells, we have generated an important genomic resource that captures the genomic information of this endangered breed at the cell level. Second, the first high-quality full-length cDNA library of Bengal tiger had been constructed and offered an efficient way to identify more genes of this majestic species. Meanwhile, expression and purification of Trx-TAT-Ferritin fusion protein showed quality and stability of the cDNA library.

\section{Acknowledgements}

This research was supported by the Ministry of Agriculture of China for transgenic research (grant no.2008ZX08009-003), the National High Technology Research and Development Program (863) of China (grant no.2007AA10Z170), Science and Technological Fund of Anhui Province for Outstanding Youth (grant no.10040606Q43) and the Key Natural Science Project of Anhui Provincial Education Department (grant no.KJ2012A199).

\section{Conflict of Interest}

The authors declare no conflict of interest.

\section{References}

1. Song, J.; Hua, S.; Song, K.; Zhang, Y. Culture, characteristics and chromosome complement of Siberian tiger fibroblasts for nuclear transfer. In Vitro Cell. Dev. Biol. Anim. 2007, 43, 203-209.

2. Taro, S.; Junco, N.; Vladimir, V.; Aramilev, A.B.; Seigo, H.; Dale, R.M. Species and sex identification from faecal samples of sympatric carnivores, Amur leopard and Siberian tiger, in the Russian Far East. Conserv. Genet. 2006, 7, 799-802. 
3. Wei, K.; Zhang, Z.H.; Zhang, W.P.; Xu, X.; Liang, X. PCR-CTPP: A rapid and reliable genotyping technique based on ZFX/ZFY alleles for sex identification of tiger (Panthera tigris) and four other endangered felids. Conserv. Genet. 2008, 9, 225-228.

4. Li, J.Y.; Wang, H.Y.; Liu, J.; Liu, Q.; Zhang, J.S.; Wan, F.C.; Liu, F.J.; Jin, S.H.; Zhang, Y.L. Transcriptome analysis of a cDNA library from adult human epididymis. DNA Res. 2008, $15,115-122$.

5. Liu, C.Q.; Lu, T.F.; Feng, B.G.; Liu, D.; Guan, W.J.; Ma, Y.H. Construction of cDNA library and preliminary analysis of expressed sequence tags from Siberian tiger. Int. J. Biol. Sci. 2010, 6, 584-589.

6. Hempstead, P.D.; Yewdall, S.J.; Fernie, A.R.; Lawson, D.M.; Artymiuk, P.J.; Rice, D.W.; Ford, G.C.; Harrison, P.M. Comparison of the three-dimensional structures of recombinant human $\mathrm{H}$ and horse L ferritins at high resolution. J. Mol. Biol. 1997, 268, 424-448.

7. Ishiwata, H.; Katsuma, S.; Kizaki, K.; Patel, O.V.; Nakano, H.; Takahashi, T.; Imai, K.; Hirasawa, A.; Shiojima, S.; Ikawa, H.; et al. Characterization of gene expression profiles in early bovine pregnancy using a custom cDNA microarray. Mol. Reprod. 2003, 65, 9-18.

8. Orino, K.; Miura, T.; Muto, S.; Watanabe, K. Sequence analysis of canine and equine ferritin $\mathrm{H}$ and L subunit cDNAs. DNA Seq. 2005, 16, 58-64.

9. Collawn, J.F.; Gowan, L.K.; Crow, H.; Schwabe, C.; Fish, W.W. Isolation and partial amino acid sequence of three subunit species of porcine spleen ferritin: Evidence of multiple $H$ subunits. Arch. Biochem. Biophys. 1987, 259, 105-113.

10. Shao, Z.T.; Cong, X.; Yuan, J.D.; Yang, G.W.; Chen, Y.; Pan, J.; An, L.G. Construction and characterization of a cDNA library from head kidney of Japanesesea bass (Lateolabrax japonicus). Mol. Biol. Rep. 2009, 36, 2031-2037.

11. Du, L.X.; Liu, S.F.; Zhu, J.; Li, H.B.; Li, S.G.; Song, X.M.; Wang, A.H. Construction of SMART cDNA library of sheep ovary and identification of candidate gene by homologous cloning. Agric. Sci. China 2007, 6, 1390-1395.

12. Wellenreuther, R.; Schupp, I.; Poustka, A.; Wiemann, S.; German cDNA Consortium. SMART amplification combined with cDNA size fractionation in order to obtain large full-length clones. BMC Genomics 2004, 5, doi:10.1186/1471-2164-5-36.

13. Chen, X.H.; Chen, Z.; Yao, H.P.; Chen, F.; Zhu, H.H.; Zhou, H.J. Construction and characterization of a cDNA library from human liver tissue with chronic hepatitis B. J. Zhejiang Univ. Sci. 2005, 6B, 288-294.

14. Li, Y.P.; Xia, R.X.; Wang, H.; Li, X.S.; Liu, Y.Q.; Wei, Z.J.; Lu, C.; Xiang, Z.H. Construction of a full-length cDNA Library from Chinese oak silkworm pupa and identification of a KK-42-binding protein gene in relation to pupa-diapause termination. Int. J. Biol. Sci. 2009, 5, 451-457.

15. Wu, H.L.; Wan, Q.H.; Fang, S.G.; Zhang, L.Y.; Xia, J.S.; Zhong, Z.Y. Construction of a cDNA library of blood of Elaphurus davidianus. Acta Theriol. Sin. 2007, 27, 380-384.

16. Al-Taweel, K.; Dilantha Fernando, W.G.; Brûlé-Babel, A.L. Construction and Characterization of a cDNA library from wheat infected with Fusarium graminearum Fg 2. Int. J. Mol. Sci. 2011, 12, 613-626. 
17. Ling, P.; Wang, M.; Chen, X.; Campbell, K.G. Construction and characterization of a full-length cDNA library for the wheat stripe rust pathogen (Puccinia striiformis f. sp. tritici). BMC Genomics 2007, 8, 145.

18. Wiemann, S.; Mehrle, A.; Bechtel, S.; Wellenreuther, R.; Pepperkok, R.; Poustka, A. cDNAs for functional genomics and proteomics: The German sonsortium. C. R. Biol.2003, 326, 1003-1009.

19. Blair, M.W.; Fernandez, A.C.; Ishitani, M.; Moreta, D.; Seki, M.; Ayling, S.; Shinozaki, K. Construction and EST sequencing of full-length, drought stress cDNA libraries for common beans (Phaseolus vulgaris L.). BMC Plant Biol. 2011, 11, 171.

20. Liu, C.Q.; Guo, Y.; Liu, D.; Guan, W.J.; Ma, Y.H. Establishment and characterization of fibroblast cell line derived from Siberian tiger (Panthera tigris altaica). Biopreserv. Biobank. 2010, 8, 99-105.

21. Ye, J.; McGinnis, S.; Madden, T.L. BLAST: Improvements for better sequence analysis. Nucleic Acids Res. 2006, 34, W6-W9.

22. Wheeler, D.L.; Barrett, T.; Benson, D.A.; Bryant, S.H.; Canese, K.; Chetvernin, V.; Church, D.M.; DiCuccio, M.; Edgar, R.; Federhen, S.; et al. Database resources of the National Center for Biotechnology Information. Nucleic. Acids Res. 2008, 36, D13-D21.

23. Thanh, T.; Chi, V.T.; Abdullah, M.P.; Omar, H.; Noroozi, M.; Ky, H.; Napis, S. Construction of cDNA library and preliminary analysis of expressed sequence tags from green microalga Ankistrodesmus convolutus Corda. Mol. Biol. Rep. 2011, 38, 177-182.

24. Thompson, J.D.; Higgin, D.G.; Gibson, T.J. CLUSTAL W: Improving the sensitive of progressive multiple sequence alignment through sequence weighting, position specific gap penalties and weigh matrix choice. Nucleic Acids Res.1994, 22, 4673-4680.

(C) 2013 by the authors; licensee MDPI, Basel, Switzerland. This article is an open access article distributed under the terms and conditions of the Creative Commons Attribution license (http://creativecommons.org/licenses/by/3.0/). 